\title{
Using an incomplete gamma function to quantify the effect of dystocia on the lactation performance of Holstein dairy cows in Iran
}

\author{
H. Atashi, ${ }^{\star 1}$ A. R. Abdolmohammadi, † A. Asaadi,‡ A. Akhlaghi, ${ }^{*}$ M. Dadpasand, ${ }^{\star}$ and Y. Jafari Ahangari§ \\ *Department of Animal Science, Shiraz University, 71441-65186 Shiraz, Iran \\ †Department of Animal Science, Razi University, 67156-85438 Kermanshah, Iran \\ $¥$ School of Veterinary Science, Shiraz University, 71345-1731 Shiraz, Iran \\ §Faculty of Animal Science, Gorgan University of Agricultural Science and Natural Resources, 49189-43464 Gorgan, Iran
}

\begin{abstract}
The aim of the present study was to estimate the effect of dystocia on lactation performance, using an incomplete gamma function. Data from March 2000 to April 2009 comprising 100,628 lactations of 65,421 cows in 204 dairy herds collected by the Animal Breeding Center of Iran were used. Of 100,628 births, $91.8 \%$ required no assistance, whereas $8.2 \%$ required assistance of some sort. Factors associated with the presence of dystocia were calving season, calving year, herd, calf sex, parity, and age of dam. Peak yield for primiparous cows with dystocia at calving occurred on $\mathrm{d} 87.2$ [standard error (SE) 0.47], and for primiparous cows with easy calving, the peak of lactation was on $\mathrm{d} 83.3$ (0.25). Peak yield was lowered by 0.39 (SE 0.07), 2.20 (SE 0.15), 2.22 (SE 0.21), and 2.54 (SE 0.32) kg for cows with incidence of dystocia compared with normal cows in parity 1 to 4 , respectively. Dystocia was associated with decreased 305-d lactation performance in all parities, mostly in early lactation. Although more difficult births occurred in heifer calvings, loss in lactation performance was greater in second or later lactations following a difficult birth.
\end{abstract}

Key words: dystocia, lactation curve, incomplete gamma function, Holstein dairy cow

\section{INTRODUCTION}

Dystocia, more commonly known as difficult calving and defined as a prolonged or difficult parturition, is a common problem on dairy farms. The problem spans from the need for increased producer attention to the loss of the cow, calf, or both. To assess the cost-benefit of diagnosis and prevention efforts, estimation of the effects of the problem on lactation performance, fertility, and survival is important. Previous reports dem-

Received September 20, 2011.

Accepted January 11, 2012.

${ }^{1}$ Corresponding author: Atashi@shirazu.ac.ir onstrated that difficult birth was a leading cause of calf death at delivery or shortly after birth and led to uterine infections, more retained placentas, and lower reproduction and lactation performance in the dams (Djemali et al., 1987; Rajala and Grohn, 1998; Berry et al., 2007; Lombard et al., 2007; Linden et al., 2009).

The use of mathematical models describing the lactation curve will enable researchers to reveal the patterns of milk loss caused by dystocia more accurately and in much more detail (Rajala and Grohn, 1998). However, very few scientific reports detail the effect of dystocia on the parameters describing the lactation curve in Holstein dairy cows. The objective of this study was to investigate the effect of dystocia on lactation curve traits and partial and 305-d lactation performance in Holstein dairy cows in Iran.

\section{MATERIALS AND METHODS}

Data from March 2000 to April 2009 comprising $1,059,412$ test-day milk records corresponding to 100,628 lactations of 65,421 cows in 204 dairy herds collected by the Animal Breeding Center of Iran were used. Edits were on the number of test-day records per cow per lactation $(>4)$, lactation length $(<320 \mathrm{~d})$, DIM at which the first test-day was recorded $(>5)$, and age at first calving (540 to 1,200 d).

The herds were under official performance and pedigree recording. The main components of the dairy ration consisted of corn silage, alfalfa hay, barley grain, fat powder, beet pulp, and feed additives. Farmers, upon observing parturition, subjectively assigned a calving ease score according to the degree of assistance provided. Recognized dystocia scores were $1=$ no problem, $2=$ slight problem, $3=$ needed assistance, $4=$ considerable force, and $5=$ extreme difficulty. In the present study, dystocia scores of 1 or 2 were coded as easy calving, and scores of $\geq 3$ were coded as difficult calvings. Data on parity number were classified into 5 categories: parity $1,2,3,4$, and $\geq 5$.

To describe the lactation curve and associated production characteristics, the incomplete gamma function 
proposed by Wood (1967) was applied in this study. The function was as follows: $y_{t}=a t^{b} e^{-c t}$, where $y_{t}$ is the daily milk yield in DIM $t$, the variable $t$ represents the length of time since calving, $e$ is the Neper number, $a$ is a parameter to represent yield at the beginning of lactation, and $b$ and $c$ are factors associated with the upward and downward slope of the curve, respectively. In the current work, the incomplete gamma function was transformed logarithmically into a linear form as $\ln \left(y_{t}\right)$ $=\ln (a)+b \ln (t)-c t$, and was fitted to monthly lactation yield records using a program written in Visual Basic (Microsoft Corp., Redmond, WA). The DIM at peak production $\left(T_{\max }\right)$ was defined as $T_{\max }=(b / c)$, expected maximum yield was calculated as $y_{\max }=$ $a(b / c)^{b} e^{-b}$, persistency $(s)$ was calculated as $s=-(b+$ 1) $\ln (c)$, and total yield from the calving up to 100,200 , and 305 DIM was calculated as $y=a \int_{1}^{n} t^{b} e^{-c t} \mathrm{~d} n$, where $n=100,200$, and 305, respectively. The effect of dystocia on the parameters describing the lactation curve, as well as partial and 305-d lactation performance, was determined using multiple regression mixed models in PROC MIXED (SAS Institute, 1999) through the inclusion of dystocia in a 2-way interaction with parity, the effect of herd, calving year, and calving season combination, covariate effect of age at first calving, and random effect of dam's sire.

\section{RESULTS}

Descriptive statistics of dystocia by parity for 100,628 lactations of 65,421 Holstein cows calving between 2000 and 2009 are presented in Table 1. Of 100,628 births, $91.8 \%$ required no assistance, whereas $8.2 \%$ required assistance of some sort. Factors associated with the presence of dystocia were calving season, calving year, calf sex, herd, parity, and age of dam $(P<0.05)$. The probability of dystocia was higher in dams giving birth to male calves than in those with female calves. First parity was associated with more difficult calving than other parities $(P<0.05)$.

A significant interaction existed between dystocia and parity for lactation performance and the parameters describing the lactation curve $(P<0.05)$. The

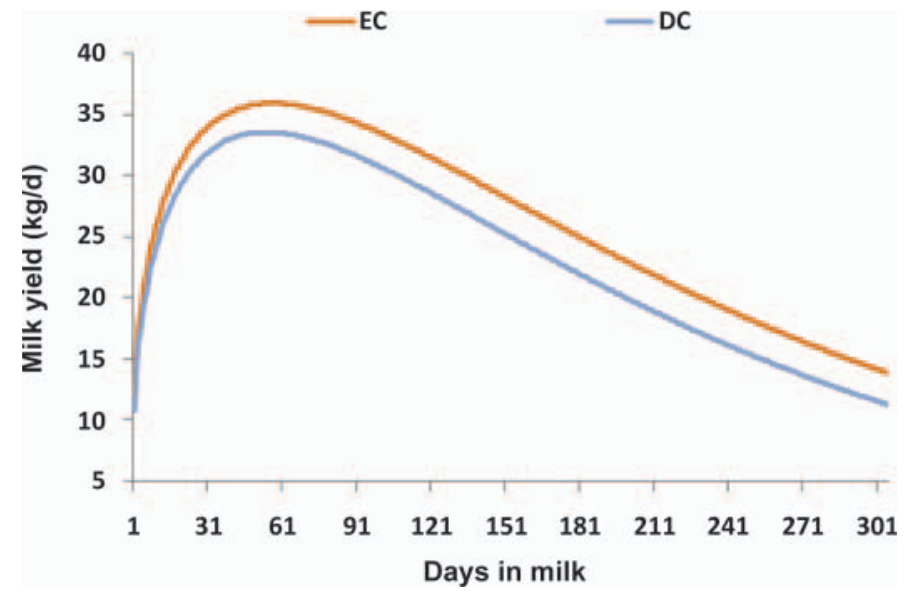

Figure 1. Lactation curves for cows with dystocia (DC, difficult calving) and for those without dystocia (EC, easy calving) at parity 4. Color version available in the online PDF.

shape of the lactation curve for cows with difficult calving tended to be lower and flatter than for those with eutocia (Figure 1). Cows that experienced dystocia at calving had lower initial yield than those that did not (Table 2). Dystocia was associated with higher DIM until peak for primiparous cows (Table 2). Peak yield (SE in parentheses) for primiparous cows with dystocia at calving occurred on $\mathrm{d} 87.2(0.47)$ and for the primiparous cows with easy calving the peak of lactation was on d 83.3 (0.25). Dystocia and peak yield were negatively associated $(P>0.05)$ in all parities except for parity $\geq 5$. Peak yield (SE in parentheses) was lower by $0.39(0.07), 2.20(0.15), 2.22(0.21)$, and $2.54(0.32)$ $\mathrm{kg}$ for cows with incidence of dystocia compared with normal cows in parity 1 to 4 , respectively. In all parities except for second and fourth, lactation persistency was higher in cows that experienced dystocia than in those that did not (Table 3).

Dystocia was associated with decreased 305-d lactation performance in all parities $(P<0.05)$. The lowest and greatest rates of decrease in 305-d lactation performance due to dystocia were found in first- and fourthlactation cows, respectively $(P<0.05)$. The reductions in 305-d lactation performance (SE in parentheses) because of dystocia were 56.6 (19.7) $\mathrm{kg}$ of milk, 1.87

Table 1. Descriptive statistics of dystocia by parity for 100,628 lactations of 65,421 Holstein cows calving between 2000 and 2009 in Iran

\begin{tabular}{lrrrrr}
\hline & \multicolumn{5}{c}{ Parity } \\
\cline { 2 - 6 } Item & 1 & 2 & 3 & 4 & $\geq 5$ \\
\hline Calvings (no.) & 63,041 & 20,519 & 9,987 & 4,893 & 2,188 \\
Difficult calvings (no.) & 6,265 & 1,078 & 538 & 237 & 134 \\
Dystocia (\%) & 9.94 & 5.25 & 5.39 & 4.84 & 6.12 \\
\hline
\end{tabular}


Table 2. Least squares means (SE) of the 2-way interaction of dystocia (EC = easy calving; DC = difficult calving) with parity for lactation curve traits ${ }^{1}$ of Holstein dairy cattle of Iran

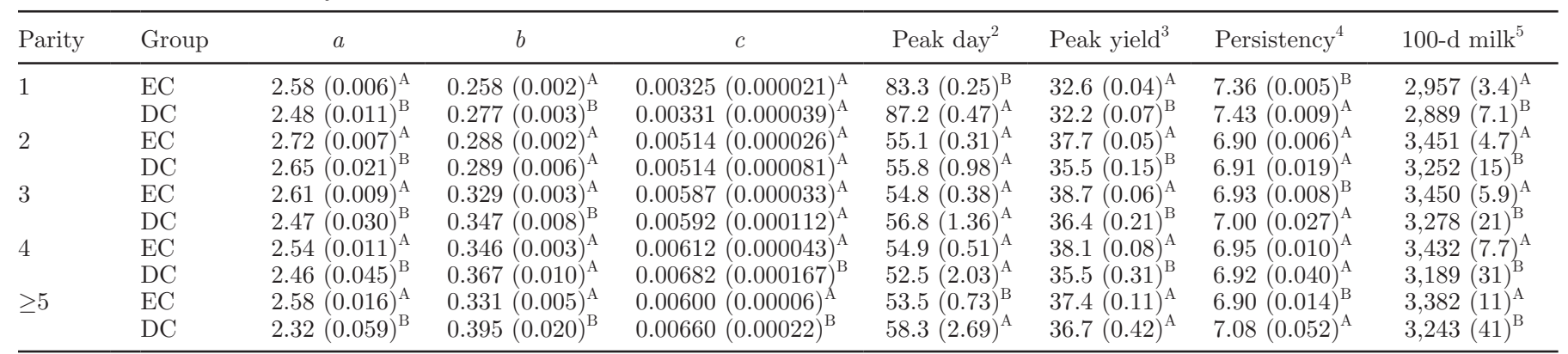

\footnotetext{
${ }^{2}$ DIM at peak yield calculated as $b / c$.

${ }^{3}$ Peak yield calculated as $a(b / c)^{b} e^{-b}$.

${ }^{4}$ Persistency calculated as $s=-(b+1) \ln (c)$.

${ }^{5}$ Total milk yield through 100 DIM calculated as $y=a \int_{1}^{100} t^{b} e^{-c t} \mathrm{~d} n$.
}

${ }_{\mathrm{A}, \mathrm{B}}$ Means with different superscripts (EC vs. DC within parity), differ significantly $(P<0.05)$

${ }^{1}$ Modeled as $\ln \left(y_{t}\right)=\ln (a)+b[\ln (t)]^{-c t}$, where $y_{t}=$ milk yield on day $t, a=$ a scaling factor to represent yield at the beginning of lactation, and $b$ and $c$ are factors associated with the inclining and declining slopes of the lactation curve.

(0.58) $\mathrm{kg}$ of fat, and $2.05(0.47) \mathrm{kg}$ of protein in first lactation, whereas corresponding values were 722.6 (96) $\mathrm{kg}$ of milk, $17.52(2.76) \mathrm{kg}$ of fat, and $19.03(2.2) \mathrm{kg}$ of protein for fourth lactation (Table 3 ).

The reduction in 305-d milk yield was dissimilar for the different stages of lactation. Although the association between dystocia and total milk yield was significant for the first $100 \mathrm{~d}$ of the lactation in all parities $(P<0.05)$ and for $\mathrm{d} 101$ to 200 in all parities except for parities $\geq 5$, the association was significant only for parities 2, 3, and 4 for d 201 to 305 (Table 3).
Total cumulative milk yield (SE in parentheses) in the first $100 \mathrm{~d}$ of lactation for cows experiencing dystocia compared with those with eutocia was reduced by 68 (6.6), 198.4 (14.9), 221.6 (20.9), 242.5 (31.4), and 138.7 (41.9) $\mathrm{kg}$ in parity 1 to parity $\geq 5$, respectively, and the corresponding values for d 101 to 200 of lactation were 22.01 (7.11), 167.8 (15.9), 151.2 (22.3), 279.1 (33.5), and 71 (44.7) $\mathrm{kg}$. The reduction in milk yield during d 201 to 305 of lactation because of dystocia was estimated to be 126.2 (19.9), 110 (27.9), and 245.8 (41.9) in parities 2,3 , and 4 , respectively.

Table 3. Least squares means (SE) of the 2-way interaction of dystocia $(\mathrm{EC}=$ easy calving; $\mathrm{DC}=$ difficult calving) with parity for lactation performance ${ }^{1}$ of Holstein dairy cattle of Iran

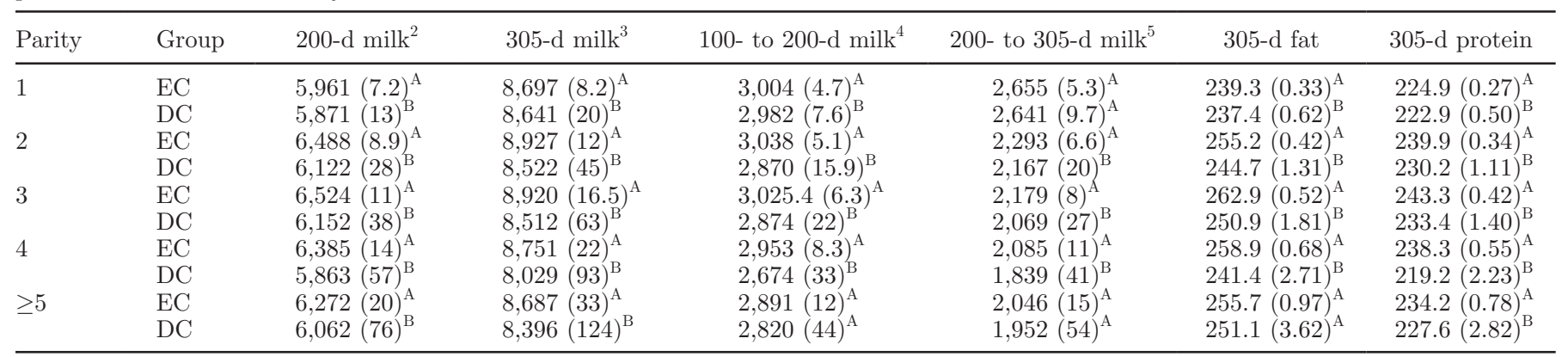

\footnotetext{
${ }_{\mathrm{A}, \mathrm{B}}$ Means with different superscripts (EC vs. DC within parity), differ significantly $(P<0.05)$ $b$ and $c$ are factors associated with the inclining and declining slopes of the lactation curve.

${ }^{2}$ Total milk yield through 200 DIM calculated as $y=a \int_{1}^{200} t^{b} e^{-c t} \mathrm{~d} n$.

${ }^{3}$ Total milk yield through 305 DIM calculated as $y=a \int_{1}^{305} t^{b} e^{-c t} \mathrm{~d} n$.

${ }^{4}$ Total milk yield from 101 to 200 DIM calculated as $y=a \int_{101}^{200} t^{b} e^{-c t} \mathrm{~d} n$.

${ }^{5}$ Total milk yield from 201 to 305 DIM calculated as $y=a \int_{201}^{305} t^{b} e^{-c t} \mathrm{~d} n$.
}

${ }^{1}$ Modeled as $\ln \left(y_{t}\right)=\ln (a)+b[\ln (t)]^{-c t}$, where $y_{t}=$ milk yield on day $t, a=$ a scaling factor to represent yield at the beginning of lactation, and 


\section{DISCUSSION}

The incidence of dystocia observed in the present study was $8.2 \%$, which was comparable to other international estimates (Berry et al., 2007; Mee, 2008; Linden et al., 2009) other than those in the United States, which were reported to be higher (Meyer et al., 2001; Johanson and Berger, 2003; Lombard et al., 2007).

Incompatibility between calf size and dam size, as well as pelvic and vulvar conformation, is likely to have a great effect on calving difficulty (Berglund et al., 2003). Dystocia has been implicated as the major cause of stillbirth, resulting in reduced lactation performance, number of calves, conception rate, and longevity, and in increased risk of developing metritis and retained placenta (Meyer et al., 2000; Berglund et al., 2003; Maizon et al., 2004; Bicalho et al., 2007; Lombard et al., 2007; Gundelach et al., 2009). Although several studies have documented the effect of dystocia on lactation performance in Holstein dairy cows (Chassagne et al., 1999; Berry et al., 2007; Bicalho et al., 2008), no comprehensive study has been carried out to quantify the effect of calving difficulties on lactation performance for different parts of the lactation curve. The results of this study showed that DIM until peak yield and persistency were higher, but the initial yield and peak yield were lower for cows with difficult calving than for those with eutocia. The association between initial yield and dystocia might be a consequence of behavioral changes caused by calving difficulty. Proudfoot et al. (2009) reported that during the 48 -h period before calving, cows with dystocia consumed $12 \%$ less DM than cows with eutocia $(14.3 \pm 1.0$ vs. $16.2 \pm 1.0 \mathrm{~kg})$ and consumed $24 \%$ less during the $24 \mathrm{~h}$ before calving $(8.3 \pm 0.7$ vs. $10.9 \pm 0.7 \mathrm{~kg} / \mathrm{d})$.

In this study, the effect of dystocia on milk yield varied among cows in different parities and in different stages of each lactation. Reports on the relationship between dystocia and lactation performance at different parities and different stages of lactation are not consistent (Djemali et al., 1987; Rajala and Grohn, 1998; Berry et al., 2007; Tenhagen et al., 2007). Berry et al. (2007) reported that total $60-$ and $270-\mathrm{d}$ milk yields were 42.0 and $61.9 \mathrm{~kg}$ less, respectively, in cows that experienced dystocia at calving compared with those that did not. Djemali et al. (1987) reported that total 305-d milk yield for cows experienced dystocia was reduced by 465,576 , and $725 \mathrm{~kg}$ in parity 1 to parity $\geq 3$, respectively, compared with those that did not. The effect of dystocia on 305-d fat yield was reported to be 20.7, 20.9, and $25 \mathrm{~kg}$ in parity 1 to parity $\geq 3$, respectively (Djemali et al., 1987). Rajala and Grohn (1998) reported no significant effect of dystocia on early lactation milk yield in first-parity cows, although a significant reduction in milk yield in the first $2 \mathrm{wk}$ postpartum was found in second-parity cows that experienced dystocia. Tenhagen et al. (2007) reported that mild and severe cases of dystocia had no significant effects on milk production, but milk production in cows after caesarean section was reduced by 5 to $10 \%$ on the first 6 milk test-days postpartum, with no significant difference observed in late lactation. Different definitions of dystocia and different statistical methods used to estimate milk loss due to dystocia could be of the main sources of these discrepancies. Some researchers use dystocia scores, usually from 1 to 5 , to indicate the level of difficulty at calving, whereas others report only assisted calving.

\section{CONCLUSIONS}

Using repeated measurements for monthly test-day milk samples to estimate the milk loss from dystocia gives more detailed results than using a summary measure, such as 305-d milk yield. The effect of dystocia on lactation performance depended on parity and stage of lactation. Although more difficult births occurred in heifer calvings, loss in lactation performance was greater in second or later lactations following a difficult birth. The reduction in lactation performance in cows after dystocia was most distinct in early lactation compared with the later stages of lactation. The results of this study may be useful for further economic analyses of dystocia, such as determining the economic weights for development of future selection indices in Holstein dairy cows.

\section{ACKNOWLEDGMENTS}

The co-operation of the Animal Breeding Center (Karaj, Iran) for providing the data is greatly appreciated.

\section{REFERENCES}

Berglund, B., L. Steinbock, and M. Elvander. 2003. Causes of stillbirth and time of death in Swedish Holstein calves examined post mortem. Acta Vet. Scand. 44:111-120.

Berry, D. P., J. M. Lee, K. A. Macdonald, and J. R. Roche. 2007. Body condition score and body weight effects on dystocia and stillbirths and consequent effects on postcalving performance. J. Dairy Sci. 90:4201-4211.

Bicalho, R. C., K. N. Galvao, S. H. Cheong, R. O. Gilbert, L. D. Warnick, and C. L. Guard. 2007. Effect of stillbirth on dam's survival and reproduction performance in Holstein dairy cows. J. Dairy Sci. 90:2797-2803.

Bicalho, R. C., K. N. Galvao, L. D. Warnick, and C. L. Guard. 2008. Stillbirth parturition reduces milk production in Holstein cows. Prev. Vet. Med. 84:112-120.

Chassagne, M., J. Barnouin, and J. P. Chacornac. 1999. Risk factors for stillbirth in Holstein heifers under field conditions in France: A prospective survey. Theriogenology 51:1477-1488. 
Djemali, M., A. E. Freeman, and P. J. Berger. 1987. Reporting of dystocia scores and effects of dystocia on production, days open, and days dry from dairy herd improvement data. J. Dairy Sci. 70:2127-2131

Gundelach, Y., K. Essmeyer, M. K. Teltscher, and M. Hoedemaker. 2009. Risk factors for perinatal mortality in dairy cattle: Cow and foetal factors, calving process. Theriogenology 71:901-909.

Johanson, J. M., and P. J. Berger. 2003. Birth weight as a predictor of calving ease and perinatal mortality in Holstein cattle. J. Dairy Sci. $86: 3745-3755$.

Linden, T. C., R. C. Bicalho, and D. V. Nydam. 2009. Calf birth weight and its association with calf and cow survivability, disease incidence, reproductive performance, and milk production. J. Dairy Sci. 92:2580-2588.

Lombard, J. E., F. B. Garry, S. M. Tomlinson, and L. P. Garber. 2007. Impacts of dystocia on health and survival of dairy calves. J. Dairy Sci. 90:1751-1760.

Maizon, D. O., P. A. Oltenacu, Y. T. Grohn, R. L. Strawderman, and U. Emanuelson. 2004. Effects of diseases on reproductive performance in Swedish Red and White dairy cattle. Prev. Vet. Med. $66: 113-126$.

Mee, J. F. 2008. Prevalence and risk factors for dystocia in dairy cattle: A review. Vet. J. 176:93-101.
Meyer, C. L., P. J. Berger, and K. J. Koehler. 2000. Interactions among factors affecting stillbirths in Holstein cattle in the United States. J. Dairy Sci. 83:2657-2663.

Meyer, C. L., P. J. Berger, K. J. Koehler, J. R. Thompson, and C. G. Sattler. 2001. Phenotypic trends in incidence of stillbirth for Holsteins in the United States. J. Dairy Sci. 84:515-523.

Proudfoot, K. L., J. M. Huzzey, and M. A. G. von Keyserlingk. 2009. The effect of dystocia on the dry matter intake and behavior of Holstein cows. J. Dairy Sci. 92:4937-4944.

Rajala, P. J., and Y. T. Grohn. 1998. Effects of dystocia, retained placenta, and metritis on milk yield in dairy cows. J. Dairy Sci. $81: 3172-3181$

SAS Institute. 1999. SAS/ STAT User's Guide. Version 8 ed. SAS Institute Inc., Cary, NC.

Tenhagen, B. A., A. Helmbold, and W. Heuwieser. 2007. Effect of various degrees of dystocia in dairy cattle on calf viability, milk production, fertility and culling. J. Vet. Med. A Physiol. Pathol. Clin. Med. 54:98-102.

Wood, P. D. P. 1967. Algebraic model of the lactation curve in cattle. Nature 216:164-165. 